\title{
Expansion of the functional abilities of the internal combustion engine exhaust gas recirculation method as a means of reducing harmful emissions
}

\author{
Nurbolat Sakenovich Sembaev ${ }^{1, *}$, Ersen Kapsamadovich Ordabaev ${ }^{2}$, Serik Imangalievich Akhmetov ${ }^{3}$, and Zhalgas \\ Zhanbolatovich Gabolla ${ }^{4}$ \\ ${ }^{1}$ associate professor, candidate of technical sciences, Department "Transport technology and logistics", NJSC "Toraigyrov University", \\ 140000, Pavlodar, Kazakhstan \\ ${ }^{2}$ associate professor, candidate of technical sciences, Department "Transport technology and logistics", NJSC "Toraigyrov University", \\ 140000, Pavlodar, Kazakhstan \\ ${ }^{3}$ doctoral student, Department "Transport technology and logistics", NJSC "Toraigyrov University", 140000, Pavlodar, Kazakhstan \\ ${ }^{4}$ undergraduate, Department "Transport technology and logistics", NJSC "Toraigyrov University", 140000, Pavlodar, Kazakhstan
}

\begin{abstract}
Road transport, as is known, provides high mobility of the population and significant cargo turnover both on a regional and interstate scale. Unlike large stationary sources of pollution, road transport is a huge number of mobile units of equipment operating in various working conditions. Therefore, the report and control of harmful car emissions is difficult. Other consequences of rapid motorization of society are traffic congestion, increased delivery time for goods and passengers, noise and stress of road users, etc. Based on the analysis of the conditions and operating modes of a car in a dense traffic flow, typical for urbanized areas, the article shows the possibility of using the well-known method of exhaust gas recirculation for a new purpose. This is the forced idle mode of the engine, which occurs when the car is braked by the engine without shutting down the transmission, which is present in modern standards for limiting harmful emissions. It is shown that in the indicated mode, it is possible to carry out complete recirculation of gases in order to achieve short-term isolation of the engine from the atmosphere. At the same time, the usage of the gas recirculation method for the main purpose is not excluded - to reduce the emission of nitrogen oxide $\mathrm{NO}$ in the engine.
\end{abstract}

\section{Introduction}

Urbanization of the population is inevitably associated with the need for its mobility and, therefore, leads to the expansion of communication links, primarily to a sharp increase in the number of cars. The main problems of rapid motorization of modern society are pollution of the air basin of cities, the occurrence of traffic jam, and an increase in noise levels, as well as a decrease in the speed of movement of goods and passengers. ).[1-2]

In the conditions of dense traffic flow typical for large cities, the car, as is known, most of the time works on sharply variable modes of acceleration, fixed steady motion, deceleration or idle in a random sequence. At the same time, this situation is typical not only for megacities. For example, experiments conducted on a single car with a manual transmission in the city of Nursultan during rush hour give similar results. In a driving cycle lasting 35 minutes, the speed of the car and engine, and the opening angle of the throttle were recorded every 5 seconds. Table 1 shows a fragment of the printout of the on-board computer data obtained during the driving tests. 
Table 1. A fragment of the printout of the on-board computer.

\begin{tabular}{|c|c|c|c|}
\hline $\begin{array}{c}\text { Period, } \\
\text { sec }\end{array}$ & $\begin{array}{c}\text { Vehicle } \\
\text { speed, } \\
\text { km/h }\end{array}$ & $\begin{array}{c}\text { Engine } \\
\text { speed, rpm }\end{array}$ & $\begin{array}{c}\text { Throttle } \\
\text { opening } \\
\text { angle }\end{array}$ \\
\hline 5 & 3.8 & 1320 & 7.8 \\
\hline 10 & 7.5 & 1120 & 6.3 \\
\hline 15 & 18.8 & 1760 & 8.6 \\
\hline 20 & 28.8 & 2200 & 3.9 \\
\hline 25 & 22.5 & 1080 & 0 \\
\hline 30 & 12.5 & 880 & 0 \\
\hline 35 & 12.5 & 1080 & 14.1 \\
\hline 40 & 31.3 & 2480 & 12.9 \\
\hline 45 & 27.5 & 1360 & 7.8 \\
\hline 50 & 28.8 & 1480 & 15.2 \\
\hline 55 & 33.8 & 1720 & 8.2 \\
\hline 60 & 28.8 & 840 & 0 \\
\hline 65 & 22.5 & 1160 & 16 \\
\hline 70 & 28.8 & 1440 & 3.5 \\
\hline 75 & 28.8 & 1480 & 12.1 \\
\hline 80 & 32.5 & 1680 & 5.9 \\
\hline 85 & 38.8 & 1960 & 13.7 \\
\hline 90 & 38.8 & 1160 & 0 \\
\hline 95 & 26.3 & 880 & 0 \\
\hline 100 & 21.3 & 880 & 0 \\
\hline 105 & 15 & 840 & 0 \\
\hline 110 & 2.5 & 840 & 0 \\
\hline 115 & 10 & 1600 & 11.3 \\
\hline 120 & 22.5 & 1760 & 4.7 \\
\hline 125 & 30 & 1880 & 3.9 \\
\hline 130 & 38.8 & 2000 & 7.4 \\
\hline 135 & 42.5 & 2160 & 1.6 \\
\hline 140 & 32.5 & 1240 & 0 \\
\hline 145 & 17.5 & 800 & 0 \\
\hline 150 & 0 & 880 & 0 \\
\hline 155 & 0 & 880 & 0 \\
\hline 160 & 0 & 880 & 0 \\
\hline 165 & 0 & 880 & 0 \\
\hline 170 & 0 & 880 & 0 \\
\hline 175 & 7.5 & 1600 & 9.8 \\
\hline 180 & 21.3 & 1800 & 21.1 \\
\hline 185 & 7.5 & 840 & 0 \\
\hline 190 & 0 & 960 & 0 \\
\hline 195 & 17.5 & 2480 & 14.5 \\
\hline 200 & 18.8 & 1000 & 0 \\
\hline 205 & 6.3 & 1560 & 0 \\
\hline 210 & 0 & 840 & 0 \\
\hline 215 & 0 & 880 & 0 \\
\hline 5 & 1.3 & 1160 & 3.5 \\
\hline
\end{tabular}

The analysis of changes in the speed of the car (Figure 1) shows that the mode of movement with $\mathrm{V}=$ const in its strict sense is practically absent. Conditionally. we can assume that the relative time of the steady-state mode of movement is $20 \%$. and the acceleration is $33 \%$. The share of self-idling and forced idling modes accounts for $47 \%$. of which the car engine braking mode takes about $17 \%$.

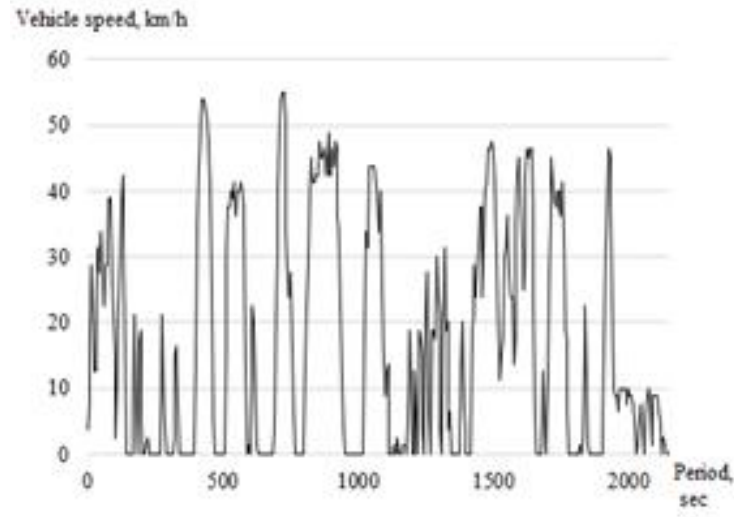

Fig. 1. The analysis of changes in the speed of the car.

The drawn conclusions are also confirmed by the analysis of changes in the engine speed (Figure 2).

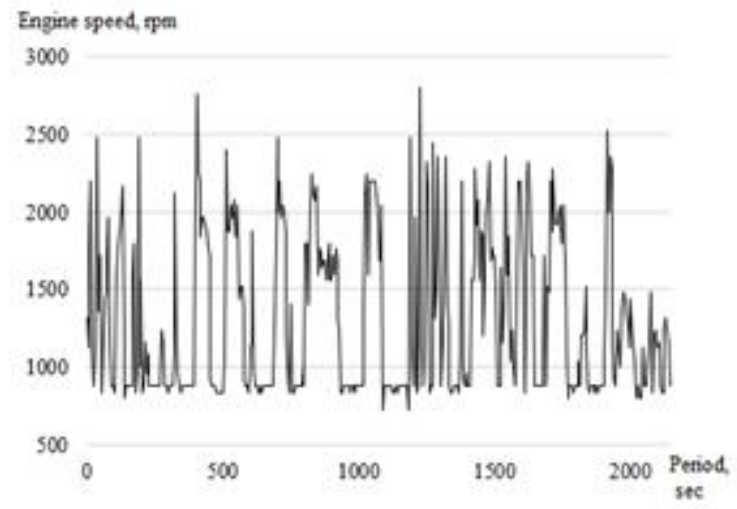

Fig. 2. Changes in the engine speed.

The fact that the modes of free idling and deceleration of the car without switching off the transmission. when the engine is running under forced idling. take up a significant part of the operating time. is reflected in modern standards. For example. in the European System for the Regulation of harmful Emissions of vehicles of categories M1 and N1 according to the European Standard (Regulations No. 15. No. 83). idling and forced idling modes together account for up to $50 \%$ of the total test time (elementary driving cycle). ).[3-8]

The mode of operation of the engine at forced idling. was named because of the forced rotation of the crankshaft during the braking of the car by the engine. It is characterized by a rapid closing of the throttle at a high speed of rotation of the crankshaft and a gradual decrease in it. At this moment. the vacuum in the intake manifold and the engine cylinder increases sharply (up to $80-85 \mathrm{kPa}$ ). At the same time. the filling of the cylinder with a fresh charge is greatly reduced and its mix with residual gases increases. as a result of which there are ignition gaps in the engine cylinder. and at high rotational speeds. combustion stops. In combination of these factors. the content of the amount of unburned hydrocarbons $(\mathrm{CH})$ in the composition of the exhaust gases increases.

Switching off the fuel supply in the forced idle mode. provided for both in carburetor and modern injection 
systems of mixing. does not solve the problem. The fact is that the above-mentioned high vacuum in the cylinder causes an intense absorption of oil from the crankcase through the leaks of the cylinder-piston and along the valve rods. As a result. despite the shutdown of the fuel supply. the incoming oil and the remaining part of the fuel film evaporating from the walls continues to "feed" the exhaust gas with hydrocarbons.

Analysis of the modes of operation of the car in the city suggests that the optimal solution to the problems of forced idling and improving the environmental safety of the car as a whole can be based on the fact that when the car is switched to deceleration mode. the engine is not required to develop power to transfer it to the driving wheels. On the contrary. when the car is decelerated by the engine and the kinematic connection is maintained in the power transmission. the engine turns into a braking device due to the presence of internal losses in it. which the kinetic energy of the car is consumed to overcome. Therefore. under these conditions. the engine can be switched to a closed gas exchange cycle with full exhaust gas recirculation. This is the idea of periodic isolation of the engine from the atmosphere with the complete cessation of gas emissions. which has a positive effect on the environmental parameters of the car and the environment as a whole [9-12]

This report is about using the gas recirculation method. which is known to be used in internal combustion engines as a means of reducing the formation of nitrogen oxide $\mathrm{NO}$ and its concentration in the exhaust gases under load conditions. The use of this method for a new purpose for forced idling modes in order to exclude the release of gases into the environment involves complete recirculation of exhaust gases in the engine. which is possible for the above reasons and has a very real justification.

In a traditional exhaust gas recirculation system. in order to reduce NO emissions. there is a mandatory on a device that changes the amount of recirculated gases. i.e. the degree of recirculation. depending on the operating parameters of the engine. mainly the load. The system under consideration is intended for use only in the forced idle mode. that is. without external load. Consequently. there is no need to regulate the recirculation of gases; instead. a recirculation valve is introduced. operating in two modes: "fully open - fully closed". At the same time. there is a demand on devices that detect the moments of the onset and end of the forced idling mode.

In this case. the system of complete gas recirculation includes a recirculation channel. approximately the same in cross-section with the intake manifold. then when it is turned on. the intake pipeline through this channel and the exhaust system will actually communicate with the environment. At very low air flow through the intake manifold (or its absence) at forced idling. a certain amount of air from the exhaust side will enter the recirculation channel. which. when mixed with the exhaust gases. will pulsate in the "intake manifold cylinder - exhaust manifold - recirculation channel intake collector"system. And the absence of a directflow purge of the intake manifold eliminates the disadvantages caused by the evaporation of the liquid fuel film from it. When switching to the traction mode of the internal combustion engine. the gases remaining in the cylinders and the intake system after forced idling will be removed in two or three working cycles. which can not have significant negative consequences.

The implementation of the proposed method is possible by connecting the exhaust pipe 2 of the engine with the intake pipe 1 using a recirculation channel 3 with an equivalent flow section and a shut-off valve 4 (Figure 3).

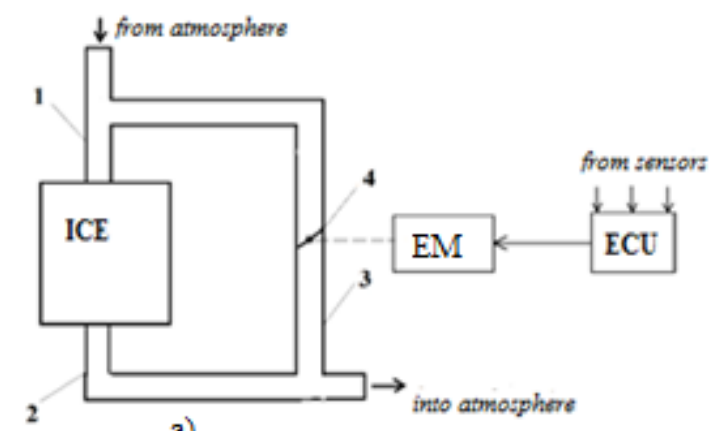

a)

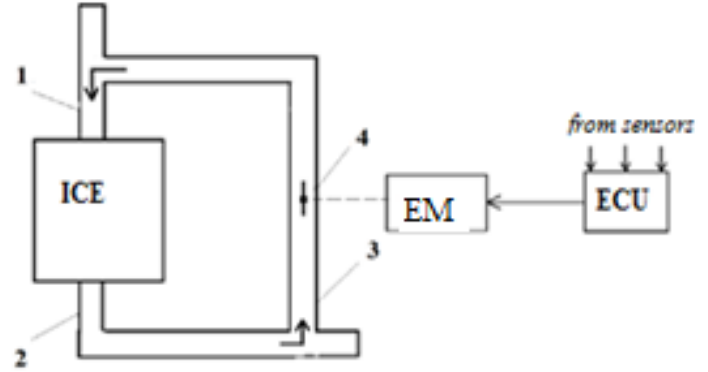

b)

Fig. 3. Gas exchange schemes of an automobile engine: a) gas exchange in the main operating modes; b) gas exchange when the car is slowed down by the engine (forced idling); ECU electronic control unit; IM-executive mechanism. 1-inlet pipe; 2-outlet pipe; 3-recirculation channel; 4-recirculation valve.

The control of the exhaust gas recirculation is based on the detection of forced idling as an engine operation mode with the throttle valve closed at a speed exceeding the minimum idling speed. using devices (sensor system. electronic engine control unit. shut-off valve actuator) known in fuel supply systems with the forced idling economizer [4]. and opening the shut-off valve of the recirculation channel for the period of the specified mode.

It should be noted that the reduction of the so-called pump losses in the engine with full exhaust gas recirculation can lead to a decrease in the braking torque of the engine in the vehicle braking mode by the engine. However. this is not of fundamental importance for modern cars equipped with efficient braking systems. [13-16]

Thus. the presented technology of complete recirculation of exhaust gases in the internal combustion engine can serve as a rational means of solving the problem of reducing emissions of harmful substances into the environment at forced idling of the car.

This article discusses the method of complete recirculation of exhaust gases as a way to reduce the 
release of toxic substances into the atmosphere. It is shown that when the car is slowed down by the engine. it is possible to isolate the engine from the environment by switching it to a closed gas exchange cycle.

Based on the analysis of the conditions and modes of operation of the car in a dense traffic flow characteristic of urbanized areas. the article shows the possibility of using the well-known method of exhaust gas recirculation for a new purpose. We are talking about the mode of forced idling of the engine. which occurs when the car is slowed down by the engine without turning off the transmission. which is present in modern standards for limiting harmful emissions. It is shown that in this mode it is possible to carry out complete recirculation of gases in order to achieve short-term isolation of the engine from the atmosphere.

It is important to note that when implementing the proposed method. the possibility of using the gas recirculation method in the same system for the main purpose to reduce the emission of nitrogen oxide NO in the engine is not excluded.

\section{References}

1. E. K. Ordabayev. Ecological safety of vehicles/ Monograph. - Pavlodar: Kereku. 2014. - p. 122.

2. E. S. Kuznetsov. VehicleTtechnical Maintenance in the USA. - Moscow:Transport. 1978. - p. 186.

3. A. R. Kulchitsky. Toxicity of vehicle and tractor engines: manual for higher education. Moscow: The Academic Project. 2004. - p. 400.

4. A. V. Dmitrievsky. E. V. Shatrov. Fuel efficiency of gasoline engines. - Moscow: Mechanical Engineering. 1985. - p. 208.

5. Commission Directive 1999/77/EC of 26 July 1999

6. https://www.un.org/ru/ecosoc/unece

7. O. I. Zhegalin. P. D. Pugachev. Reducing the toxicity of vehicle engines. - Moscow: Transport. 1985. - p. 120.

8. E. K. Ordabayev. The problems of forced idle speed of a carburetor engine // Vehicle manufacturing industry. 1 (1986).

9. A. N. Tikhomirov. "Ozon" and "Weber" carburetors. - Moscow: Koleso Publishing Office. 2002. - p. 64.

10. K. Yakubovsky. Motor vehicle and environmental protection: Translator with graphics. - Moscow : Transport. 1979. - p. 198

11. A. N. Voinov. Combustion in high-speed reciprocating engines. - Moscow: Mechanical Engineering. 1977. - p. 277.

12. A. P. Gussarov. Nitrogen oxides as the main problem of ATS developers //Vehicle manufacturing industry. - 1992. No. 8. - p. 13-15.

13. V. A. Zvonov. Toxicity of inner combustion engines. - Moscow: Mechanical Engineering. 1981. - p. 160.
14. V. I. Smylis. Low-toxic diesels. - Leningrad: Mechanical Engineering. 1972. - p. 128.

15. E. K. Ordabayev. S. I. Akhmetov. and V. S. Essaulkov. Science and Technology of Kazakhstan. 1 (2019).

16. E. K. Ordabayev. S. I. Akhmetov. Vestnik mashinostroeniya. 11 (2019). 